\title{
Adaptation to climate change: tools and methods
}

\author{
Jill Jäger $\cdot$ Peter Moll
}

Received: 9 February 2010/Accepted: 15 August 2010/Published online: 28 August 2010

(C) Springer-Verlag 2010

After the Copenhagen Conference in December 2009, it is more obvious than ever that adaptation to climate change is inevitable. Both the scientific and the policy communities will have to devote more attention to the issue of adaptation in the coming years. In this special issue, we focus on the tools and approaches that will be needed to meet the challenge of adaptation to climate change.

This special issue is based on papers presented at a session at the Climate Change Congress held in Copenhagen in March 2009, which aimed to synthesize the current state of scientific knowledge on the issue of climate change as an input to the deliberations that were to take place at the end of the same year. Several important questions were addressed in the session and are examined in more detail here: What methods and tools are available to support adaptation decisions and also contribute to sustainable development? What kind of information and what communication channels are needed for adaptation decisions to be made in good time and in the right place? What general approaches to research and development are needed given the wide range of stakeholders to be involved and their diverse interests to be respected in adaptation measures?

As pointed out by Banaszak and colleagues (in this issue), different people have different perceptions of the risks that they are facing and this leads to conflicts related to the implementation of adaptation measures. People filter

J. Jäger $(\bowtie)$

Vienna, Austria

e-mail: jill.jaeger@speed.at

P. Moll

Science Development, Wuppertal, Germany

e-mail: moll@science-development.de the information that they receive about a risk through preexisting mental models, which cannot be changed easily. Groups of individuals sharing the same models are better able to communicate with each other and share their learning, while communication with groups with a different mental model is more difficult. Extreme events appear to provide opportunities to stimulate changes of mental models. Furthermore, participation both in decision-making and in reaping the benefits of action can also lead to such changes.

The topic of "mental models" is also a focus of the paper by Valkering et al. (this issue), who use a multipleperspective approach as part of participatory scenario development. Taking the different perspectives of actors into account can contribute to more robust and flexible strategies for climate change adaptation. Valkering et al. show that during the process, the perspectives can change, for example as a result of context developments or learning among the participants. A change of perspective means that either the participants change their position or the dominance of particular perspectives shifts. An example is presented for climate change adaptation in the Netherlands. The results demonstrate the learning that took place when the perspectives approach was used.

A comprehensive approach to provide decision support for adaptation is presented by Daniell and colleagues (in this issue), who note the need for capacity building and coordination over multiple governance levels. In addition to illustrating the variety of multilevel processes and the different actor groups engaged at each level, they also show the multitude of different policy domains that affect the adaptation to climate change (e.g. land use, water, transport and energy policy). Adaptation to climate change requires coordination over multiple levels of governance to arrive at acceptable local, regional and global management 
strategies. However, setting up and maintaining such processes of coordination and decision support over time is a major challenge. Daniell and colleagues use four regionally focussed, multi-level case studies to illustrate how this challenge can be met.

Multiple levels of governance are also addressed by Tàbara (in this issue), who uses the "climate learning ladder", a tool presented in the session at the Copenhagen Climate Congress, to analyse the emergence of climate strategies and capacities in Catalonia, north-east Spain. Tàbara examines four main dimensions: (1) how perceptions on climate change have evolved in this region since the beginning of the 1990s; (2) what type of incentives or systems of sanctions have been put in place; (3) what specific options for agents' transformations and collaboration are available or have been developed; and (4) what new institutional arrangements have been implemented during this time. Results indicate that although new climate appraising processes have been tried and new institutions have been created in Catalonia, little substantive or differentiated progress on Integrated Climate Governance has been achieved.

One important but often neglected approach for dealing with complex issues is scenario development and analysis. Several papers in this special issue use scenarios. Bohunovsky and colleagues (in this issue) describe and analyse three projects with participatory scenario development. They conclude that scenario development is important in order to get a holistic view of the situation and the possible future and to stimulate dialogue on "what would happen if..." The analysis of different scenarios can build a solid basis for decision-making. Experience shows that stakeholder participation in scenario development and analysis allows the inclusion of a wider range of ideas and knowledge and plays an important role in empowerment of the stakeholders. Furthermore, the development of scenarios at the local level shows particular promise, not only because of the proximity to the level of implementation but also because the scenarios at this level can be much more concrete.

As Bassi (in this issue) points out, there is a need for integrated simulation tools to close the gap between dynamic and holistic thinking and the available static models. He suggests that a combination of optimization (defines goals), econometrics (identifies real correlations within systems) and simulation (investigates causal relations) provides a dynamic tool with stated goals that is grounded on but not limited to observed phenomena. The T21 model has been developed in this way and applied in a wide range of settings worldwide by the Millennium Institute. Results show the emergence of various unexpected side effects and also that elements of policy resistance arise over the medium and longer term due to interactions between energy and society, economy and environment. The use of the T21 model in a range of projects has contributed to increased understanding of the context (social, economic, environmental and political) in which issues arise and within which policies are formulated and implemented. Other papers (Daniell et al., Valkering et al. and Banaszak et al. in this issue) also show the importance of context (and perspectives) for dealing with adaptation.

The linking of knowledge with action is the focus of the paper by Beck (in this issue), who asks in particular whether the challenges and specific needs of adaptation can be properly addressed by using the IPCC model of linking science and policy. This model is essentially a very linear one, which assumes that the scientists reach consensus and that this is the basis for policy making. Beck argues that this linear model will limit the scientific and political discussions on climate change adaptation. The IPCC approach is the wrong tool for addressing the needs of adaptation, particularly because it fails to engage with alternative approaches to framing problems (addressed by Banaszak and colleagues and Valkering) and generating ideas for solving problems (addressed in the papers on approaches and tools). What is needed is a broad and iterative dialogue between assessments and their "users", adapted to the local context of decision-making. The approaches that are needed for adaptation must open up deliberations on response options rather than forcing premature closure.

For knowledge to be influential in decision-making, it must be tailored towards the demands of decision-makers, which remains a challenge in the field of climate change adaptation. The demand of decision-makers has, to date, not sufficiently been taken into account in the researchbased production of knowledge for adaptation: a huge gap remains between the conceptual work on the supply side and the concrete needs of decision-making. This is demonstrated in most papers in this special issue.

The papers here focus on the need for participatory, integrated (holistic), iterative, and, in particular, implementation-oriented research to deal effectively with the challenging issue of adaptation to climate change. The development of adaptation strategies requires transdisciplinary approaches that meet the demands of local and regional climate change adaptation decision-making. Important elements of new approaches to adaptation decision-making are indicated through this collection of papers, including social learning, scenario development and analysis, and the use of new tools.

At the same time, however, the papers and the discussion during the session at the Copenhagen Climate Congress point to serious gaps between the identified need for implementation-oriented work with new tools and approaches at the local/regional level and the availability 
of funding to carry out this kind of work. Researchers seldom receive a mandate to become engaged in the implementation of measures identified in transdisciplinary projects on the complex issues of global change. Indeed, the evaluation criteria for research proposals often mean that implementation-oriented research is rejected, because the goals of the project cannot be clearly defined a priori, since they depend on stakeholder input. Long-term funding for iterative processes that incorporate evaluation and learning is also rarely available. Furthermore, training or capacity building for this kind of research is not widely available and academic credit is still given largely for products such as peer-reviewed papers rather than engagement in policy and implementation-oriented processes.

Meeting the growing challenge of adaptation to climate change requires that these serious gaps in research design, funding and education are addressed and that respective action is taken. 